\title{
HIV-1 capture and antigen presentation by dendritic cells: enhanced viral capture does not correlate with better T-Cell activation
}

\author{
M Rodriguez-Plata1*, A Urrutia², S Cardinaud², M Buzon', N Izquierdo-Useros', JG Prado', M Puertas', I Erkizia', \\ P Coulon ${ }^{2}$, S Cedeño ${ }^{1}$, B Clotet $^{1}$, A Moris $^{3}$, J Martinez-Picado ${ }^{1}$
}

From AIDS Vaccine 2012

Boston, MA, USA. 9-12 September 2012

\section{Background}

During HIV-1 infection, dendritic cells (DC) facilitate dissemination of HIV-1 while trying to trigger adaptive antiviral immune responses. We examined whether increased HIV-1 capture in DC matured with lipopolysaccharide (LPS) results in more efficient antigen presentation to HIV-1-specific CD $4^{+}$and $\mathrm{CD} 8^{+} \mathrm{T}$ cells. In order to block the DC-mediated trans-infection of HIV-1 and maximize antigen loading, we also evaluated a non-infectious integrase-deficient HIV-1 isolate, the HIV $\mathrm{NLA-3 \Delta IN}_{\text {. }}$

\section{Methods}

Immature $\mathrm{DC}(\mathrm{iDC})$, mature $\mathrm{DC}(\mathrm{mDC})$ activated with IL-1 $\beta$, TNF- $\alpha$, IL- 6 , and PGE2 (ITIP) or LPS during viral uptake, and fully $\mathrm{mDC}$ matured with ITIP or with LPS for $48 \mathrm{~h}$ before viral loading were tested. Antigen presentation to HIV-1-specific $\mathrm{CD}_{4}^{+}$and $\mathrm{CD} 8^{+} \mathrm{T}$ cell clones was quantified by IFN- $\gamma$ ELISPOT. DC-associated p $24^{\mathrm{Gag}}$ HIV-1 and DC-mediated HIV-1 trans-infection were also evaluated in parallel.

\section{Results}

We showed that higher viral capture of DC did not guarantee better antigen presentation or T-cell activation. Greater HIV $_{\text {NL4-3 }}$ uptake by fully LPS-matured DC resulted in higher viral transmission to target cells but poorer stimulation of $\mathrm{HIV}-1$-specific $\mathrm{CD} 4^{+}$and $\mathrm{CD} 8^{+} \mathrm{T}$ cells. Conversely, maturation of DC with LPS during-but not before-viral loading enhanced both HLA-I and HLAII HIV-1-derived antigen presentation. On the other hand, DC maturation with ITIP during viral uptake only stimulated HIV-1-specific $\mathrm{CD}^{+}{ }^{+} \mathrm{T}$ cells. Integrasedeficient HIV $_{\mathrm{NL4}-3 \Delta I N}$ was also efficiently captured and presented by DC through HLA-I and HLA-II pathways, but in absence of viral dissemination.

\section{Conclusion}

Hence, DC maturation state, activation stimulus, and time lag between DC maturation and antigen loading impact HIV-1 capture and virus antigen presentation. Our results demonstrate a dissociation between the capacity to capture HIV-1 and to present viral antigens. HIV $\mathrm{NL}_{\text {L-3 }} \mathrm{IN}$ seems to be an attractive candidate to be explored. These results provide new insights into DC biology and have implications in the optimization of DC-based immunotherapy against HIV-1 infection.

\section{Author details}

'AIDS Research Institute IrsiCaixa, Badalona, Spain. ${ }^{2}$ INSERM, UMRS-945, Infection and Immunity, Université Pierre et Marie C, Paris, France. ${ }^{3}$ INSERM, UMRS-945, Infection and Immunity, Univ. Pierre et Marie Curie, Paris, France.

Published: 13 September 2012

\section{doi:10.1186/1742-4690-9-S2-P2}

Cite this article as: Rodriguez-Plata et al: HIV-1 capture and antigen presentation by dendritic cells: enhanced viral capture does not correlate with better T-Cell activation. Retrovirology 2012 9(Suppl 2):P2.

AIDS Research Institute IrsiCaixa, Badalona, Spain

Full list of author information is available at the end of the article

(c) 2012 Rodriguez-Plata et al; licensee BioMed Central Ltd. This is an Open Access article distributed under the terms of the Creative 